\title{
ISOLAMENTO E SELEÇÃO DE FUNGOS FILAMENTOSOS COM ATIVIDADE DE CELULASE ISOLADOS EM ÁREAS DE FLORESTA AMAZÔNICA MERIDIONAL
}

$\underline{\text { llio Fealho de Carvalho }}{ }^{1}$, Cintia Graciele da Silva ${ }^{2}$, Jaqueline Aline Gerhardt ${ }^{3}$, Rubens Monti ${ }^{4}$, Maurecilne Lemes da Silva ${ }^{5}$

${ }^{1}$ Professor Doutor do Departamento de Ciências Biológicas, Universidade do Estado de Mato Grosso - UNEMAT, Tangará da Serra, MT, Brasil. (iliocarv@gmail.com)

${ }^{2}$ Mestranda do Programa de Pós-Graduação em Genética e Melhoramento Vegetal Universidade do Estado de Mato Grosso - UNEMAT, Tangará da Serra, MT, Brasil.

${ }^{3}$ Graduada em Ciências Biológicas, Universidade do Estado de Mato Grosso UNEMAT. Tangará da Serra, MT, Brasil.

${ }^{4}$ Professor Doutor do Departamento de Alimentos e Nutrição, Faculdade de Ciências Farmacêutica, Universidade do Estado de são Paulo - UNESP, Araraquara, SP, Brasil.

${ }^{5}$ Professora Doutora do Departamento de Ciências Biológicas, Universidade do Estado de Mato Grosso - UNEMAT, Tangará da Serra, MT, Brasil.

Recebido em: 08/09/2015 - Aprovado em: 14/11/2015 - Publicado em: 01/12/2015 DOI: http://dx.doi.org/10.18677/Enciclopedia_Biosfera_2015_251

\begin{abstract}
RESUMO
As celulases produzidas por fungos filamentosos atuam sobre materiais celulósicos levando a degradação das fibras de celulose em açúcares como a glicose, celobiose e outros oligômeros. O trabalho teve por objetivo isolar e selecionar fungos filamentosos de diferentes áreas de floresta na região do médio norte do Estado de Mato Grosso com atividade de celulase. Foram isoladas 145 linhagens de amostras de solo e avaliadas o potencial de atividade de celulase pela técnica do halo de hidrólise do carboximetilcelulose (CMC) utilizado como fonte de carbono. Destas $50,68 \%$ das linhagens apresentaram índice enzimático (le) e 49,31\% não apresentaram halo de hidrólise ou não cresceram. As linhagens com (le) foram avaliadas para a produção de endoglucanase (CMCase) em meio sintético contendo CMC. Foi obtido um percentual de $94,59 \%$ de linhagens produtoras da enzima CMCase. As linhagens 12, 26, 42, 45, 60, 63 e 72 se destacaram como melhores produtoras de CMCase com atividade variando de 0,63 a 0,8 U.mL $\mathrm{mL}^{-1}$.
\end{abstract}

PALAVRAS CHAVE: Floresta Amazônica, Índice enzimático, Atividade de celulase.

\section{SELECTION OF FILAMENTOUS FUNGI WITH CELLULASE ACTIVITIES, ISOLATED FROM DE AMAZON FOREST}

\begin{abstract}
The cellulases produced by filamentous fungi act on cellulosic materials leading to degradation of the cellulose fibers in sugars such as glucose, cellobiose and other oligomers. The study aimed to isolate select filamentous fungi with cellulase activity from different areas of forest in the middle north of the State of Mato Grosso. We isolated 145 strains from soil samples and evaluated the potential of cellulase activity
\end{abstract}


using the halo technique of hydrolysis of carboxymethylcellulose (CMC) as a carbon source. $50.68 \%$ of the strains showed enzymatic index (le) and $49.31 \%$ did not present hydrolysis halo or did not grow. Strains with (le) were evaluated for the production of endoglucanase (CMCase) in a synthetic medium containing CMC. It was obtained from a percentage of $94.59 \%$ enzyme-producing strains CMCase. The lines 12, 26, 42, 45, 60, 63 and 72 they stood out as best CMCase-producing with activity ranging 0.63 to $0.8 \mathrm{U} . \mathrm{mL}^{-1}$.

KEY WORDS: Amazon forest, enzymatic index, cellulase activity.

\section{INTRODUÇÃO}

O solo é considerado um reservatório natural para os micro-organismos, onde aqueles com capacidade de secretar enzimas, como as celulases que atuam na decomposição da biomassa lignocelulósica, realizam atividade primordial no ciclo do carbono (DAMASO et al., 2012; VALENCIA \& CHAMBERGO, 2013). As celulases produzidas por fungos filamentosos atuam sobre materiais celulósicos levando a degradação das fibras de celulose em açúcares como a glicose, celobiose e outros oligômeros (DAMASO et al., 2012).

A hidrólise enzimática da celulose é catalisada por enzimas altamente específicas que constituem um complexo celulolítico, denominado de hidrolases, que clivam as ligações $O$-glicosídicas. A sua classificação é de acordo com seu local de atividade no substrato celulósico e compreende três grandes grupos de enzimas, as endoglucanases (EnG), que clivam ligações internas da fibra celulósica, as exoglucanases (ExG) que atuam na região externa da celulose e as e $\beta$-glicosidases (BG) que hidrolisam oligossacarídeos solúveis em glicose (CASTRO \& JUNIOR, 2010).

As enzimas produzidas por micro-organismos tiveram a sua produção comercialmente em meados de 1980 e usado com êxito em escala industrial para catalisar vários processos químicos, como a produção de detergentes, alimentos e bebidas, ração animal, têxteis, papel e celulose e produtos biomédicos (CASTRO \& JUNIOR, 2010; RIBEIRO et al., 2014). Neste contexto, os fungos filamentosos tem despertado o interesse para bioprospecção por apresentarem crescimento rápido, facilidade nas condições de cultivo, por serem bons produtores de enzimas extracelulares com grande potencial de utilização na indústria (SIMÕES \& TAUKTORNISIELO, 2005).

As celulases são utilizadas industrialmente na bioconversão de resíduos de lignocelulose e transformados em açúcar fermentável que pode ser aplicado para produção de etanol de segunda geração (GOMES et al., 1993). A produção deste tipo de etanol a partir de resíduos lignocelulósicos demonstra viabilidade de produção para o setor de biocombustíveis, por ser considerada uma fonte de energia renovável. Entretanto, a hidrólise da biomassa lignocelulósica incluem processos de pré tratamento com tecnologia de enzimas para a conversão da celulose e hemicelulose em açúcares fermentáveis. As formas de obtenção das enzimas é o maior obstáculo devido ao alto custo de produção (HE JUNA, et al., 2013; VALENCIA \& CHAMBERGO, 2013).

O Brasil possui uma grande biodiversidade que pode ser explorado para estudos com micro-organismos que tenham atividade celulolíticas. O bioma Amazônico ocupa aproximadamente metade do território brasileiro e considerada a maior reserva de diversidade biológica com solo e clima que favorecem o crescimento de micro-organismos (THIEME et al., 2007). O objetivo do trabalho foi 
isolar e selecionar fungos filamentosos de áreas de floresta da Amazônica Meridional do Estado de Mato Grosso visando à obtenção de linhagens promissoras para produção de enzimas celulolíticas.

\section{MATERIAL E MÉTODOS}

\section{Área de estudo e coleta de amostras de solo}

As atividades foram realizadas no município de Tangará da Serra, localizado no médio norte do Estado do Mato Grosso, nos meses de Maio e Julho de 2010 nas Fazendas São Marcelo (F1) (1446'46,70"S, 5751'38, 04" O), Fazenda Bahia (F2) (1437'27,15"S, 57'25'15,84" O) e Fazenda Paraíso: (F3) (14\%0'7,91"S, $5723^{\prime} 14,15^{\prime \prime}$ O), conforme figura 1. As áreas de col etas possuem vegetação com características estacionais semideciduais e submontanas (RADAM BRASIL 1982).

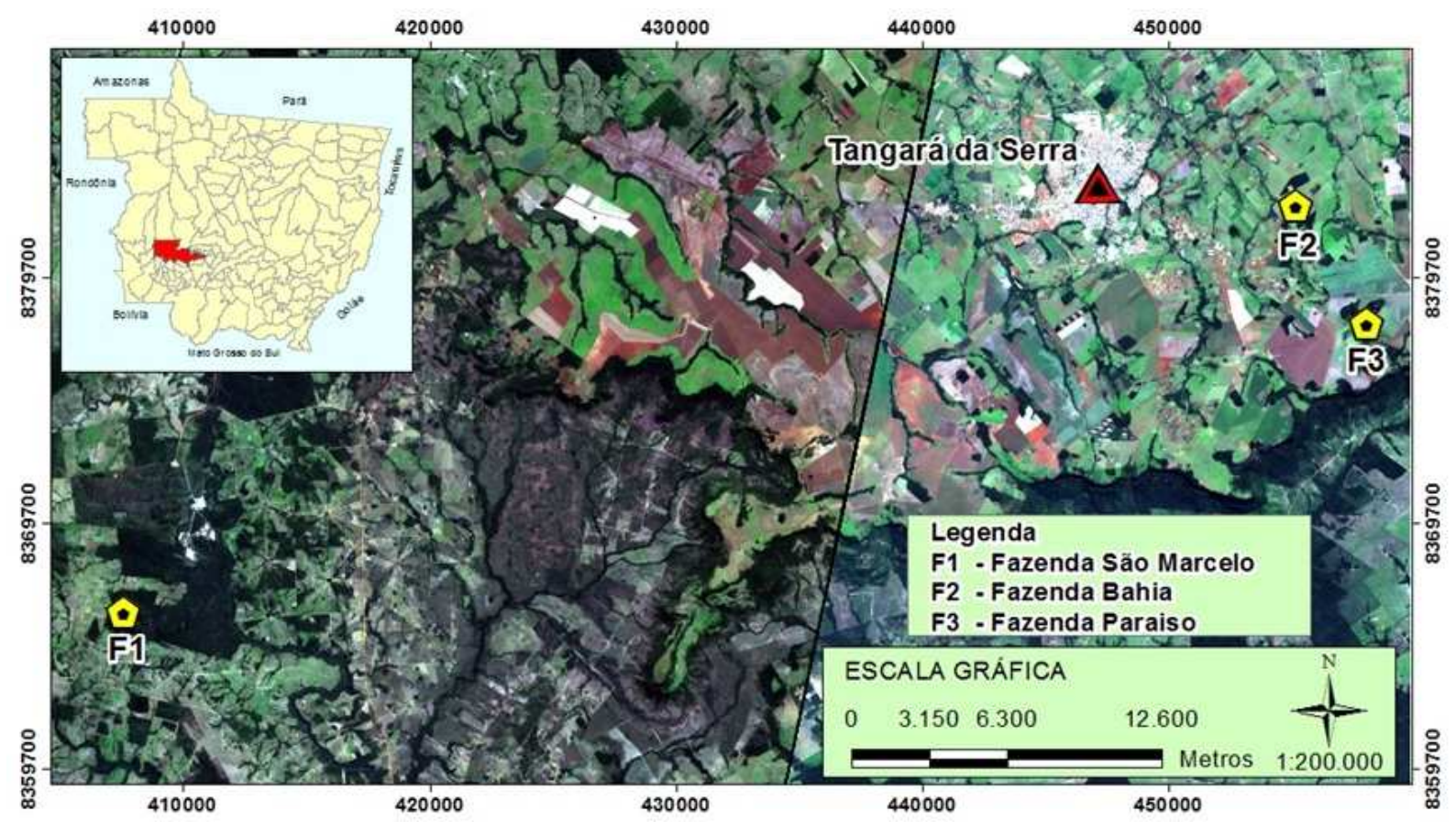

FIGURA 1: Mapa indicando as áreas de estudo localizadas nas Fazendas, município de Tangará da Serra - MT.

Foram realizadas duas coletas em cada ponto, totalizando seis amostras, sendo que cada amostra composta de solo foi constituída por cinco subamostras, obtidas da camada superficial do solo até $15 \mathrm{~cm}$ de profundidade, entre espaços de 3 a 10 metros e posteriormente, colocadas em sacos de polietileno esterilizados e armazenadas em caixas térmicas contendo gelo para a conservação conforme ADELL et al., (2002).

\section{Isolamento e manutenção}

As subamostras foram homogeneizadas e retirado $5,0 \mathrm{~g}$, para a composição da amostra com 25,0 g para cada ponto. O isolamento foi realizado através da técnica de diluição seriada e alíquotas das suspensões foram inoculadas em placas 
de Petri contendo meio BDA (Batata Dextrose Agar) contendo $200 \mathrm{mg} \cdot \mathrm{L}^{-1}$ do antibiótico cloranfenicol e incubadas em estufa tipo BOD a $28{ }^{\circ} \mathrm{C}$ por quatro dias. Após as linhagens foram purificadas e estocadas em tubos contendo meio BDA mantidas a $4{ }^{\circ} \mathrm{C}$, segundo ADELL et al., (2002).

\section{Seleção das linhagens}

As 145 linhagens de fungos isoladas foram avaliadas para selecionar as melhores produtoras de enzimas celulases. As linhagens foram inoculadas com alça tipo agulha em placas de Petri contendo meio sintético contendo (CMC) carboximetilcelulose $\left(10,0 \mathrm{~g} \cdot \mathrm{L}^{-1}\right)$ como única fonte de carbono, $\mathrm{NaNO}_{3}\left(3,0 \mathrm{~g} \cdot \mathrm{L}^{-1}\right)$, $\mathrm{K}_{2} \mathrm{HPO}_{4}\left(1,0 \mathrm{~g} \cdot \mathrm{L}^{-1}\right), \mathrm{MgSO}_{4}\left(0,5 \mathrm{~g} \cdot \mathrm{L}^{-1}\right), \mathrm{KCl}\left(0,5 \mathrm{~g} \cdot \mathrm{L}^{-1}\right), \mathrm{FeSO}_{4} \cdot 7 \mathrm{H}_{2} \mathrm{O}\left(10,0 \mathrm{mg} \cdot \mathrm{L}^{-1}\right)$, ágar $\left(20,0 \mathrm{~g} \cdot \mathrm{L}^{-1}\right)$. O pH foi ajustado em $\pm 6,8$ e incubadas por 5 dias a $28 \stackrel{\circ}{\circ}$, em estufa bacteriológica. Após as placas foram submetidas a choque térmico por $16 \mathrm{~h}$ a temperatura de $50^{\circ} \mathrm{C}$. Posteriormente, adicionou-se $10 \mathrm{~mL}$ de solução corante vermelho congo a 2,5 g. $\mathrm{L}^{-1}$ em tampão Tris $\mathrm{HCl} 0,1 \mathrm{M}, \mathrm{pH} 8,0$. Decorrido 30 minutos a solução foi descartada e as culturas foram lavadas com $5 \mathrm{~mL}$ de solução de $\mathrm{NaCl}$ 0,5 M no mesmo tampão de acordo com NOGUEIRA \& CAVALCANTE (1996).

$O$ índice enzimático foi mensurado com um paquímetro em a relação ao diâmetro do halo de degradação e o diâmetro do halo da colônia de acordo com RUEGGER \& TAUK-TORNISIELO (2004). As colônias que apresentaram índice enzimático foram selecionadas para avaliação da produção de endoglucanase (CMCase).

\section{Avaliação da atividade de CMCase}

Para a avaliação da produção de CMCase, as 74 linhagens fúngicas selecionadas foram cultivadas meio sintético contendo (CMC) $\left(10,0 \mathrm{~g} \cdot \mathrm{L}^{-1}\right), \mathrm{NaNO}_{3}$ $\left(3,0 \mathrm{~g} \cdot \mathrm{L}^{-1}\right), \mathrm{K}_{2} \mathrm{HPO}_{4}\left(1,0 \mathrm{~g} \cdot \mathrm{L}^{-1}\right), \mathrm{MgSO}_{4}\left(0,5 \mathrm{~g} \cdot \mathrm{L}^{-1}\right), \mathrm{KCl}\left(0,5 \mathrm{~g} \mathrm{~L}^{-1}\right), \mathrm{FeSO}_{4} \cdot 7 \mathrm{H}_{2} \mathrm{O}(10,0$ $\left.\mathrm{mg} . \mathrm{L}^{-1}\right)$ e ágar $\left(20,0 \mathrm{~g} \cdot \mathrm{L}^{-1}\right)$, pH ajustado em 5.0 e esterilizados a $121 \stackrel{\circ}{\mathrm{C}}$ por 15 minutos. Após cada frasco foi inoculados com $2 \mathrm{~mL}$ de uma suspensão $1 \times 10^{7}$ esporos. $\mathrm{mL}^{-1} \mathrm{e}$ incubados em cultivo estático em estufa Bacteriológica (BOD) a temperatura de $28 \stackrel{\circ}{\circ}$, durante 14 dias, de acordo com RUEGGER \& TAUKTORNISIELO (2004). O cultivo foi realizado em duplicatas.

\section{Determinação da produção de CMCase}

A atividade de CMCase foi determinada através da mistura de $10 \mathrm{~mL}$ de tampão acetato de sódio $50 \mathrm{Mm}$ pH 5,0,5mL extrato enzimático e 1,0\% de CMC. Após, a mistura foi incubada a $50^{\circ} \mathrm{C}$, por 90 minuto s. Nos tempos determinados alíquotas de $0,5 \mathrm{~mL}$ da mistura foram retiradas e transferidas para tubos, onde a reação foi interrompida pela adição de $0,5 \mathrm{~mL}$ de ácido-3,5-dinitrosalicílico (DNS) e os conteúdos foram fervidos por 5 minutos. Após o resfriamento foi adicionado $5 \mathrm{~mL}$ de água destilada, e a mistura foi lida em espectrofotômetro na absorbância de 540 $\eta \mathrm{m}$. A quantidade de açúcar redutor liberado foi determinado usando a glicose como padrão de acordo com a metodologia de MILLER (1959). Uma unidade de atividade da enzima $(U)$ foi definida como a quantidade de enzima que libera $1 \mu \mathrm{mol}$ de produto formado por minuto nas condições do ensaio. Para avaliação da produção enzimática das linhagens de fungos filamentosos mais promissores foi realizado 0 tratamento estatístico através do Teste agrupamento Scott-Knott. 


\section{RESULTADOS E DISCUSSÃO}

$\mathrm{Na}$ avaliação da atividade de celulase das 145 linhagens isoladas e cultivadas em meio contendo CMC utilizando-se a coloração com vermelho congo pode-se identificar que 50,68\% (74) das linhagens apresentaram (le) índice enzimático e $49,30 \%$ (72) não apresentaram halo ou não cresceram. As linhagens que se destacaram na atividade de hidrólise de CMC foram às linhagens 26 com 9,26, 12 com 7,0 e a 19 com 6,35, revelando maiores índices enzimáticos e diferindo estatisticamente das demais linhagens avaliadas, conforme observado na Tabela 1.

Os resultados obtidos neste estudo possibilitam inferir que o ambiente onde as coletas foram realizadas favoreceu a obtenção de linhagens produtoras de celulases, tendo em vista que a floresta Amazônica são áreas com muita serapilheira, ou seja, rico em biomassa o que favorece e estes ambientes são preferencias para o desenvolvimento de fungos com atividade devido a sua capacidade de produção e secreção de enzimas lignocelulósicas para degradação da biomassa (VALÊNCIA et al., 2013). De acordo com RIBEIRO et al. (2014) o Brasil tem uma grande diversidade de micro-organismos por compreender um vasto território físico, onde existem grandes áreas de florestas e a diversidade vegetal, e ainda poucos estudados. Os autores enfatizam que além de identificar fungos filamentosos produtores de celulase, podem ainda encontrar outros fungos com excelentes produtores de xilanases e lacases.

As linhagens que apresentaram (le) cultivadas em meio contendo CMC como fonte de carbono foram avaliadas para produção de CMCase. Os resultados obtidos demonstraram que sete linhagens, identificadas como 12, 26, 42, 45, 60, 63 e 72 apresentaram produção enzimática de CMCase variando de 0,63 a $0,8 \mathrm{U} \cdot \mathrm{mL}^{-1}$, deferindo estatisticamente das demais linhagens avaliadas (Tabela 2). Observamos que os resultados para a atividade de CMCase destas linhagens poderiam ser melhoradas com a suplementação de outras fontes de carbono. El-HADI et al., (2014) relatam a produção de CMCase por Aspergillus horatai em meio líquido, após $96 \mathrm{~h}$ de cultivo, conseguiram obter uma produção máxima de $0,23 \mathrm{U} \cdot \mathrm{mL}^{-1}$, entretanto, quando suplementaram o meio com lactose a atividade de CMCase aumento para $1,18 \mathrm{U} \cdot \mathrm{mL}^{-1}$. Isto indica que vários fatores podem afetar a bioconversão da celulose, como o tempo de cultivo, quantidade do inóculo, valores de $\mathrm{pH}$, temperatura ideal e meio de cultivo.

RUEGGER \& TAUK-TORNISIELO (2004) em estudos com fungos filamentosos isolados de amostras de solo e selecionados através da técnica de halo da hidrólise enzimática observaram le somente em $45 \%$ das linhagens de fungos. Já LIAO et al., (2015) cultivando a linhagem Penicillium oxalicum GZ-2 em meio contendo casca de arroz obtiveram uma atividade para CMCase de 2,0 U.mL ${ }^{-1} \mathrm{e}$ JUNG et al., (2015) em estudo com outra linhagem de Penicillium sp. isolado de amostras de solo cultivado em meio mineral contendo celulase microcristalina como fonte de carbono apresentou atividade enzimática para CMCase de 1,27 U. $\mathrm{mL}^{-1}$.

Atualmente, as celulases estão sendo aplicadas na produção de etanol de segunda geração em que incluem tecnologia de enzimas e de processos de pré tratamento de resíduos para conversão de celulose/hemicelulose em açúcares fermentáveis (DIAS et al., 2011). Outra tendência é o grande interesse no desenvolvimento de tecnologias limpas e sustentáveis que possibilitem a utilização de produtos de interesse biotecnológico e de processos, com o menor impacto ambiental possível (JEGATHEESAN et al., 2009). 
TABELA 1 Atividade da celulase através do índice enzimático de fungos filamentosos cultivados em meio sintético $(\mathrm{CMC}) . \varnothing \mathrm{h}=$ média do diâmetro do halo $(\mathrm{mm}) ; \varnothing c$ = média do diâmetro da colônia $(\mathrm{mm})$; le = índice enzimático.

\begin{tabular}{|c|c|c|c|c|c|c|c|}
\hline Linhagens & $\varnothing \mathrm{h}$ & $\varnothing c$ & IE & Linhagens & $\varnothing \mathrm{h}$ & $\varnothing c$ & IE \\
\hline 1 & 20,25 & 12,25 & $1,57 \mathrm{a}$ & 38 & 55,25 & 22,50 & $2,74 b$ \\
\hline 2 & 17,75 & 11,25 & $1,49 a$ & 39 & 33,25 & 25,50 & $1,29 \mathrm{a}$ \\
\hline 3 & 9,00 & 8,50 & $1,38 a$ & 40 & 43,25 & 35,25 & $2,79 \mathrm{~b}$ \\
\hline 4 & 13,25 & 12,70 & $1,32 \mathrm{a}$ & 41 & 38,75 & 19,75 & $1,63 \mathrm{a}$ \\
\hline 5 & 13,00 & 10,00 & $1,32 \mathrm{a}$ & 42 & 20,50 & 9,50 & $2,45 b$ \\
\hline 6 & 7,75 & 7,50 & $1,48 \mathrm{a}$ & 43 & 28,75 & 10,00 & $3,15 b$ \\
\hline 7 & 22,00 & 17,25 & $1,32 \mathrm{a}$ & 44 & 20,75 & 15,75 & $1,55 \mathrm{a}$ \\
\hline 8 & 41,50 & 40,00 & $1,38 \mathrm{a}$ & 45 & 56,25 & 49,75 & $1,12 \mathrm{a}$ \\
\hline 9 & 11,50 & 6,75 & $1,70 \mathrm{a}$ & 46 & 12,75 & 11,50 & $1,25 \mathrm{a}$ \\
\hline 10 & 28,75 & 23,50 & $1,23 a$ & 47 & 24,00 & 11,25 & $2,48 b$ \\
\hline 11 & 16,30 & 11,50 & $2,43 b$ & 48 & 15,00 & 7,75 & $1,23 \mathrm{a}$ \\
\hline 12 & 25,00 & 3,75 & $7,00 \mathrm{c}$ & 49 & 18,25 & 10,25 & $1,56 \mathrm{a}$ \\
\hline 13 & 6,00 & 3,25 & $1,53 \mathrm{a}$ & 50 & 6,50 & 5,00 & $1,45 \mathrm{a}$ \\
\hline 14 & 20,25 & 8,00 & $1,28 \mathrm{a}$ & 51 & 17,75 & 12,50 & $1,46 \mathrm{a}$ \\
\hline 15 & 62,75 & 54,50 & $1,15 \mathrm{a}$ & 52 & 18,25 & 10,00 & $1,47 \mathrm{a}$ \\
\hline 16 & 32,25 & 13,00 & $2,42 b$ & 53 & 26,75 & 15,25 & $1,34 \mathrm{a}$ \\
\hline 17 & 13,50 & 3,25 & $2,65 b$ & 54 & 24,00 & 12,25 & $1,95 \mathrm{~b}$ \\
\hline 18 & 38,20 & 28,70 & $1,39 a$ & 55 & 28,00 & 17,25 & $1,76 \mathrm{a}$ \\
\hline 19 & 11,00 & 6,00 & $6,35 c$ & 56 & 60,50 & 55,25 & $2,31 \mathrm{~b}$ \\
\hline 20 & 18,00 & 8,75 & $1,54 \mathrm{a}$ & 57 & 20,00 & 8,75 & $1,34 \mathrm{a}$ \\
\hline 21 & 21,25 & 11,50 & $2,27 \mathrm{~b}$ & 58 & 30,50 & 11,00 & $1,27 \mathrm{a}$ \\
\hline 22 & 59,50 & 56,70 & $1,91 \mathrm{~b}$ & 59 & 12,74 & 8,75 & $2,05 \mathrm{~b}$ \\
\hline 23 & 9,75 & 4,00 & $1,17 \mathrm{a}$ & 60 & 33,75 & 28,50 & $2,22 b$ \\
\hline 24 & 29,75 & 12,50 & $2,39 \mathrm{~b}$ & 61 & 13,00 & 7,25 & $1,93 \mathrm{~b}$ \\
\hline 25 & 27,00 & 22,25 & $1,40 \mathrm{a}$ & 62 & 19,25 & 13,25 & $2,03 \mathrm{~b}$ \\
\hline 26 & 21,00 & 8,25 & $9,26 \mathrm{~d}$ & 63 & 25,75 & 25,75 & $1,14 \mathrm{a}$ \\
\hline 27 & 33,75 & 13,50 & $1,47 \mathrm{a}$ & 64 & 22,00 & 9,25 & $1,93 \mathrm{~b}$ \\
\hline 28 & 23,00 & 7,75 & $2,75 b$ & 65 & 25,50 & 20,75 & $1,61 \mathrm{a}$ \\
\hline 29 & 17,25 & 11,75 & $1,51 \mathrm{a}$ & 66 & 25,00 & 18,25 & $1,98 \mathrm{~b}$ \\
\hline 30 & 26,25 & 8,25 & $3,59 b$ & 67 & 20,50 & 14,25 & $1,43 a$ \\
\hline 31 & 54,50 & 38,50 & $2,40 \mathrm{~b}$ & 68 & 20,75 & 10,75 & $1,86 \mathrm{~b}$ \\
\hline 32 & 57,25 & 48,50 & $2,13 b$ & 69 & 10,50 & 3,75 & $2,20 \mathrm{~b}$ \\
\hline 33 & 18,00 & 17,00 & $1,05 \mathrm{a}$ & 70 & 22,75 & 10,00 & $1,60 \mathrm{a}$ \\
\hline 34 & 23,00 & 14,50 & $1,99 \mathrm{~b}$ & 71 & 23,25 & 11,25 & $2,09 \mathrm{~b}$ \\
\hline 35 & 16,25 & 10,75 & $2,48 \mathrm{~b}$ & 72 & 16,00 & 12,25 & $2,20 \mathrm{~b}$ \\
\hline 36 & 47,25 & 32,75 & $1,25 \mathrm{a}$ & 73 & 21,25 & 17,25 & $2,05 \mathrm{~b}$ \\
\hline 37 & 54,00 & 30,00 & $2,73 b$ & 74 & 13,25 & 11,50 & $1,82 \mathrm{a}$ \\
\hline
\end{tabular}

Médias seguidas da mesma letra não diferem entre si pelo teste de Scott-Knott ao nível de $5 \%$ de probabilidade. 
TABELA 2. Determinação da atividade de CMase das linhagens de fungos filamentosos, cultivados em meio sintético (CMC).

\begin{tabular}{|c|c|c|c|}
\hline Linhagens & U. $\mathrm{mL}^{-1}$ & Linhagens & U. $\mathrm{mL}^{-1}$ \\
\hline 1 & $0,26 \mathrm{~b}$ & 38 & $0,43 d$ \\
\hline 2 & $0,43 d$ & 39 & $0,33 \mathrm{c}$ \\
\hline 3 & $0,26 \mathrm{~b}$ & 40 & $0,40 \mathrm{~d}$ \\
\hline 4 & $0,54 \mathrm{e}$ & 41 & $0,18 b$ \\
\hline 5 & $0,01 \mathrm{a}$ & 42 & $0,63 \mathrm{f}$ \\
\hline 6 & $0,40 \mathrm{~d}$ & 43 & $0,34 \mathrm{c}$ \\
\hline 7 & $0,32 c$ & 44 & $0,22 b$ \\
\hline 8 & $0,32 \mathrm{c}$ & 45 & $0,63 \mathrm{f}$ \\
\hline 9 & $0,50 \mathrm{~b}$ & 46 & $\mathrm{NO}$ a \\
\hline 10 & $0,23 b$ & 47 & $0,24 \mathrm{~b}$ \\
\hline 11 & $0,45 c$ & 48 & $0,30 \mathrm{c}$ \\
\hline 12 & $0,74 \mathrm{f}$ & 49 & $0,40 \mathrm{~d}$ \\
\hline 13 & $0,44 \mathrm{~d}$ & 50 & $0,47 \mathrm{~d}$ \\
\hline 14 & $0,50 \mathrm{e}$ & 51 & $0,33 c$ \\
\hline 15 & $0,05 \mathrm{a}$ & 52 & $0,52 \mathrm{e}$ \\
\hline 16 & $0,28 b$ & 53 & $0,27 b$ \\
\hline 17 & $0,24 \mathrm{~b}$ & 54 & $0,13 b$ \\
\hline 18 & $0,25 b$ & 55 & $0,16 \mathrm{~b}$ \\
\hline 19 & $0,23 b$ & 56 & $0,33 \mathrm{~b}$ \\
\hline 20 & $0,44 d$ & 57 & $0,33 \mathrm{c}$ \\
\hline 21 & $0,25 \mathrm{f}$ & 58 & $0,34 \mathrm{c}$ \\
\hline 22 & $0,22 b$ & 59 & $0,01 \mathrm{a}$ \\
\hline 23 & $0,33 \mathrm{~b}$ & 60 & $0,63 \mathrm{f}$ \\
\hline 24 & $0,11 \mathrm{a}$ & 61 & $0,20 \mathrm{a}$ \\
\hline 25 & $0,20 \mathrm{a}$ & 62 & $0,21 \mathrm{~b}$ \\
\hline 26 & $0,80 \mathrm{f}$ & 63 & $0,63 \mathrm{f}$ \\
\hline 27 & $0,47 d$ & 64 & $\mathrm{NO}$ a \\
\hline 28 & $0,34 \mathrm{c}$ & 65 & $0,24 \mathrm{~b}$ \\
\hline 29 & $0,23 b$ & 66 & $0,22 b$ \\
\hline 30 & $0,30 \mathrm{a}$ & 67 & $\mathrm{NO}$ a \\
\hline 31 & $0,24 \mathrm{~b}$ & 68 & $\mathrm{NO} a$ \\
\hline 32 & $0,33 \mathrm{c}$ & 69 & $0,12 \mathrm{a}$ \\
\hline 33 & $0,24 \mathrm{~b}$ & 70 & $0,16 \mathrm{~b}$ \\
\hline 34 & $0,25 b$ & 71 & $0,34 \mathrm{c}$ \\
\hline 35 & $0,25 b$ & 72 & $0,70 \mathrm{f}$ \\
\hline 36 & $0,27 \mathrm{~b}$ & 73 & $0,07 \mathrm{a}$ \\
\hline 37 & $0,16 \mathrm{~b}$ & 74 & $0,13 b$ \\
\hline
\end{tabular}

NO = atividade enzimática não observada. Médias seguidas da mesma letra não diferem entre si pelo teste de Scott-Knott ao nível de $5 \%$ de probabilidade.

GERHARDT; et al, (2015) em estudos com fungos filamentosos isolados da região Amazônica no norte do Estado de Mato Grosso, cultivaram oito linhagens de fungos pré selecionados em meio contendo CMC como fonte de carbono e avaliaram a atividade de CMCase, constataram que as linhagens de Aspergillus I e Penicillium II apresentaram atividade de CMCase de 0,71U.mL-1 e 0,61 U.mL ${ }^{-1}$, e 
estas linhagens foram consideradas promissoras na atividade celulase. Ribeiro et al., (2014) destacam a importância de estudos com fungos isolados da floresta Amazônica produtores de celulases e que ainda existem micro-organismos desconhecidos que podem ser excelentes produtores destas enzimas.

\section{CONCLUSÃO}

Das 146 linhagens de fungos filamentos avaliadas 74 linhagens apresentaram índice enzimático, sendo que a linhagem 26 se destacou com maior índice enzimático 9,26. Entretanto, as linhagens que apresentaram índice enzimático a maioria produziram a enzima CMCase, indicando que a técnica através do halo de degradação de CMC é promissora para a seleção de fungos filamentosos com atividade celulolítica. As linhagens mais promissoras tiveram uma produção de CMCase variando de $0,74 U \cdot \mathrm{mL}^{-1}$ a $0,80 \mathrm{U} \cdot \mathrm{mL}^{-1}$.

\section{REFERÊNCIAS}

ADELL, C.; LUCON, C. M. M.; KOIKE, C. M. Biodiversidade do Gênero Trichoderma no estado de São Paulo - Aspectos enzimáticos e potencial biocontrolador. Arquivos do Instituto Biológico, v. 69, Supl. p. 188-191, 2002.

CASTRO, A. M.; JUNIOR, N. P. Produção, propriedades e aplicação de celulases na hidrólise de resíduos agroindustriais. Química Nova, v. 33, n.1, p. 181-188, 2010.

DAMASO, M. C. T.; TERZI, S. C.; FARIAS, A. X.; OLIVEIRA, A. C. P.; FRAGA, M. E.; COURI, S. Selection of cellulolytic fungi isolated from diverse substrates. Brazilian Archives of Biology and Technology, v. 55, n.4, p. 513-520, 2012.

DIAS, M.O.; CUNHA, M.P.; JESUS, C.D.; ROCHA, G.J.; PRADELLA, J.G.; ROSSELL, C.E; FILHO, R.M.; BONOMI, A. Second generation ethanol in Brazil: can it compete with electricity production? Bioresource Technology, n.102, p. 89648971, 2011.

EL-HADI, A. A.; EL-NOUR, S. A.; HAMMAD, A.; KAMEL. Z.; ANWAR, M. Optimization of cultural and nutritional conditions for carboxymethylcellulase production by Aspergillus hortai. Journal of Radiation Research and Applied Sciences, v. 7, p. 23-28, 2014.

GERHARDT, J. A.; CARVALHO, I. F.; SILVA, M. L.; POLIZELI, M. L. T. M.; ALNOCH, R. C. Avaliação da atividade celulolítica de fungos filamentosos isolados de amostras de solo da região norte do estado de Mato Grosso. Enciclopédia Biosfera, v. 11, n.21, p. 1971-1981, 2015.

GOMES, J.; PURKARTHIOFER, H.; KAPPLOMILLER, J.; SINNNER, M.; STEINER, $W$. Production of high level of cellulase-free xylanase by the thermophilic fungus, Thermomyces lanuginosus in laboratory and pilot scales using lignocellulosic materials. Applied Microbiology Biotechnology, v. 39, p. 700-707, 1993. 
JUNA, H.; GUANGYEB, H., DAIWEN, C. Insights into enzyme secretion by filamentous fungi: Comparative proteome analysis of Trichoderma reesei grown on different carbon sources. Journal of Proteomics, v. 89, p. 191-201, 2013.

JEGATHEESAN, V., LIOW, J.L., SHU, L., KIM, S.H., AND VISVANATHAN, C. The need for global coordination in sustainable development. Journal of Cleaner Production,v 7, n.17, p. 637-643, 2009.

JUNG. Y. R.; PARK. J. M.; HEO. S.Y.; HONG. W. K.; LEE. S. M.; OH. B. R.; PARK. S. M.; SEO. J.W.; KIM. C. H. Cellulolytic enzymes produced by a newly isolated soil fungus Penicillium sp. TG2 with potential for use in cellulosic ethanol production. Renewable Energy, v. 76, p. 66-71, 2015.

LIAO, H.; FAN, X.; MEI, X.; WEI, Z.; RAZA, W.; SHEN, Q.; XU, Y. Production and characterization of cellulolytic enzyme from Penicillium oxalicum GZ-2 and its application in lignocellulose saccharification. Biomass and Bioenergy, v. 74, p. 122134, 2015.

MILLER, G. L. Use of dinitrosalicylle acid for determination of reducing sugar. Analytical Chemistry, v. 31, n.3, p. 426-428, 1959.

NOGUEIRA, E. B. S; CAVALCANTI, M. A. Q. Cellulolytic fungi isolated from processed oats. Revista de Microbiologia, v. 27, n.1. p. 7-9, 1996.

RADAMBRASIL, Projeto: levantamento de recursos naturais. Brasil. Boletim Técnico. Ministério das Minas e Energia. Folha SD. 1 Cuiabá. Rio de Janeiro, v. 26, p. 25-175, 1982.

RIBEIRO, L. F. C.; RIBEIRO, L. F.; JORGE, J. A.; POLIZELI, M.L.T.M. Screening of Filamentous Fungi for Xylanases and Cellulases Not Inhibited by Xylose and Glucose. British Biotechnology Journal, v. 4, n.1, p. 30-39, 2014.

RUEGGER, M. J. S.; TAUK-TORNISIELO. S. M. Atividade da celulase de fungos isolados do solo da Estação Ecológica de Juréia-Itatins, São Paulo, Brasil. Revista Brasileira de Botânica, v. 27, n.2, p. 205-211, 2004.

SIMÕES, M. L. G.; TAUK-TORNISIELO, S. M. Comparação da técnica tradicional e do método turbidimétrico automatizado no cultivo em diferentes fontes de carbono de fungos filamentosos isolados de solo de área de caatinga. Holos Environment, v. 5, n.2, p. 94-103, 2005.

THIEME, M.; LEHNER, B.; ABELL, R.; HAMILTON, S. K.; KELLNDORFER, J.; POWELL, G. Fresh water conservation planning in data-poor areas: an example from a remote Amazonia basin (Madre de Dios River, Peru and Bolivia). Biological Conservation, v. 135, n.4, p. 484-501, 2007.

VALENCIA, E. Y.; CHAMBERGO, F.S.; Mini-review: Brazilian fungi diversity for biomass degradation. Fungal Genetics and Biology, v. 60, p. 9-18, 2013. 